\title{
Analysis on College Foreign Language Teaching and Cultivation of Chinese Culture Core Values
}

\author{
Xiaodan Hou, Yongliang Ma, Yingli Shen \\ School of Foreign Languages, Hebei University of Technology, Tianjin, 300122, China
}

Key words: College English, Chinese culture, Core values.

\begin{abstract}
With the deepening of globalization, foreign language teaching becomes more important. In the process of foreign language teaching, cultivation of values plays an important and significant role. People in different countries have different values, and different values will have an effect on people's judgment on things, and communication methods. To cultivate students' better international communication skills, according to the development direction of world cultures and status of foreign language teaching, to strengthen the cultivation of Chinese culture core values in the process of foreign language teaching is particularly important. This paper conducts discussion and analysis related to this issue.
\end{abstract}

\section{Introduction}

Foreign language teaching is an essential element in college teaching, and along with the development of society, it attracts more and more attention and concern. In recent years, the level of foreign language teaching has continuous development and progress, and teachers attach more importance to the effect of different cultures and values in foreign language teaching. At present, there are mainly two aspects of culture teaching research in China: one is the research on aphasia for mother tongue cultural education, mainly related to causes of aphasia, foreign culture introduction principles, mother tongue education status and so on; the other one is taking humanistic spirit as the core concept for research and observation on foreign language teaching. This paper analyzes the trend and status of foreign language development, and explores the necessity of Chinese culture core values cultivation in foreign language teaching, to obtain new revelation and development path for foreign language teaching.

\section{The important role and significance of values in international communication}

Values mainly refer to people's attitude tendency and judgment criteria on the existence significance and value of people, things and other objects. Different countries have different cultures, and under the influence of different cultures, different values emerge. Values will reflect the social needs and common emotional tendency of people and it is the benchmark for people to judge and evaluate. Some scholars systematically categorize this judgment criterion or emotional tendency as values system (or ideas). Different languages or different cultures can reflect different values of different ethnic groups. This difference can affect the way people communicate with each other; therefore, cultivation of students' positive values is essential in the process of learning foreign languages.

The main purpose of college foreign language teaching is to cultivate students' ability of international communication and the difference of culture and ideas will have some impact in the process of international exchange. Therefore, to guide students to establish correct values and understand different values in different countries is essential for developing students' practical foreign language communication skills. Under normal circumstances, values will not be embodied by 
people's manners, or dress, but it has a very significant effect in international communication. If in the process of communication, speakers have different values, their assumed premise is somewhat different, and they will make judgment and evaluation on outside information according to their own ideas and thoughts, with their own cultural characteristics remained, but individuals do not have the right to interfere others' values, and force others to move closer to their values. Therefore, different values are likely to cause conflicts and contradictions in the process of international communication. In recent years, with the deepening of European and American culture, students will be affected more and more deeply, resulting in that students gradually lose the sense of identity for Chinese cultural values, and western culture and values become the mainstream. In the deepening process of western culture, Chinese are really influenced by western culture in terms of clothing, food, music, festivals, and other aspects, and they are inclined to ideology and values of western culture. This situation becomes intensified, which leads to that growing groups of young people become proponents of western values, to the contrary, their understanding on Chinese culture becomes shallower, national sentiment is weakened, and national self-confidence is always lacking.

Survey data shows that currently, in the international cultural market, the United States accounts for a large share of about $45 \%$, EU countries account for about $40 \%$, while China and some Asia-Pacific countries account for only $4 \%$. There are serious discrepancies between the share proportion in the cultural market and the current development in China. China has rich cultural heritage but accounts for little share in the international cultural market, which deserves our attention. Therefore, we should pay attention to cultivate culture values of teenagers, establish core values with Chinese characteristics and unique cultural character, so as to show Chinese characteristics in the process of international communication, and enhance students' international communication skills and level, to embody the true role and significance of college foreign language teaching.

\section{Differences between Chinese and western values}

\section{Chinese concept of "unity of heaven and man" and western concept of "separation of heaven and man”}

In China, "unity of heaven and man" describes the relationship between the heaven and man, and this concept has been throughout the entire history of China, mainly expressing the unity, coexistence and harmony between man and nature. Man can achieve harmony and unity with the natural environment through his cultivation. In China, the concept of "unity of heaven and man” has a long history and also has a certain practical significance in today's society. Western philosophical concepts and ideas are quite different. In western concept, everything in the world has certain contrariety. Either nature or material can be against spirit, as two opposite parts. For example, if someone can not realize his ideal or purposes, he may be affected by "destiny" in Chinese traditional values. While, western values system thinks this phenomenon is caused by the laziness and lack of spiritual struggle. So, in western values, if one follows providential development, he will be despised and spurned.

\section{Chinese "collectivism" and western "individualism"}

In Chinese cultural concept, human is part of the group, and the derived part from social relations , therefore, Chinese tend to pay more attention to the social value of human, and group can bring out the value of the individual. This concept is also influenced by "unity of heaven and man", so in the Chinese traditional concept, people tend to first meet the needs of group, for which they can sacrifice their own interests. People need group to reflect their value, and no one can leave the group. They can achieve self-realization when in risk for the group and self-worth needs to be recognized by the group. Different from Chinese cultural concept, western cultural concept tends to pay more emphasis on personal independence, human dignity and freedom, so it requires people to be responsible for their own development. Affected by the values in a long term, westerns form a more self-centralized attitude of life. Western concept holds that the relationship between any individual and either family or other groups is transitory and this is a strong "individualism” orientation, widely recognized and sought after in western countries.

\section{Chinese concept of "seeking stability" and western concept of "seeking change”}


Under the influence of traditional Confucian ideas, Chinese are often complacent, and stable values is formed after a long time. Chinese generally believe that the state cannot be unstable, family cannot disperse, and harmony of family and the state is the foundation of national and social development. In Chinese long cultural history, Chinese have been seeking progress and development in "stability", which is the fundamental basis of Chinese social development. In this regard, westerns are fundamentally different from Chinese. They like constant “change”, innovation and development of things, laissez-faire and free personal development, continuously providing the society with new impetus and direction.

\section{Chinese concept of "neutrality and harmony" and western concept of "interests and power"}

Affected by Chinese traditional culture concept foundation and core, China is quite different from western countries in social development direction and national character. Compared with westerns, Chinese pay more attention to abstinence, and pursue stability and harmony; while westerns pay attention to competition between people, pursuit of power and rights and so on. Therefore, in Chinese values, neutrality and harmony are the most important, while in western values, interests and power are essential.

In summary, China and western countries are quite different in terms of culture. A large number of studies and data show the difference of collectivism and individualism will have an impact in several ways. Especially in international communication, difference of values and culture will seriously affect the way of communication. In non-western culture, social status is supreme, and to gain wealth by exploiting others is not conducive to society. In the United Kingdom, in the written expression, "I" must be capitalized; "he”, “you”, "they” and other pronouns do not need to be capitalized all the time. This may reflect that western countries respect the individual. In English dictionary, there are about 100 words taking "self” as a prefix (e.g., self-esteem, self-awareness, etc.), which shows the important social status of "individual" in western countries. Therefore, China and Western countries are extremely different in terms of personal values. We need to deeply explore individualism orientation in western society, in order to have more in-depth understanding of western culture, thus enhancing the level and quality of foreign language teaching.

\section{To strengthen cultivation of Chinese core values in college foreign language teaching}

Different countries have different historical and cultural norms, different cultures shape values of different ethnic groups, and these differences can lead to contradictions and conflicts in national communication, which is the basic factor resulting in collision of Chinese and western culture. During western language learning, Chinese will be definitely exposed to a variety of western culture and western ideas, and they will subconsciously accept western values in the process of learning. In western values, to show personal values, develop individual potential, and constantly explore and innovate and other concepts have certain positive significance. But individualism and hedonism are negative to some degree. The negative values are the inevitable product in the development process of culture and values. Chinese college students are the future of China, and their values is related to Chinese future development direction and prosperity of Chinese nation, therefore, we have to stand on a different point of view, cultivate students to establish scientific values and value orientation, and adopt positive and scientific education ways and means. This is the problem every educator must consider.

\section{To strengthen cultivation of Chinese core values in college English teaching}

The survey shows that values of modern university students are generally inclined to individualism. Personal development has a certain influence and important significance on the society, but cooperative unity of man and social relations and correct understanding of society are also essential. Considering the situation of college students' values, we first need to start with classroom teaching.

Foreign language teachers in college and universities should have some knowledge and understanding of oriental and western cultures, provided with the corresponding insight and analysis capabilities. This requires teachers to enrich their cultural knowledge through various ways and learn about the culture in different countries. In the process of teaching, teachers cannot be limited to book 
knowledge, but need to read a wide range of extra-curricular materials, to create a cross-cultural opportunity for students, and on the basis of improving their own quality and ability, gradually guide students to develop diversified cultural concepts and communication ways. In the teaching process, teachers can deeply analyze and discuss rich cultural significance and cultural context hidden in sentence or words, also use "cultural discuss" way to encourage students to learn about different ideas and cultural values. For example, teachers can lead students to discuss the topic of "freedom", exchanging in pairs in foreign language, one student discussing with western values, and the other student discussing with Chinese values, thereby, enhancing students' understanding and identity for different cultures, thus promoting students to form core values in line with Chinese culture and development.

To strengthen cultivation of Chinese core values in college English extra-curricular activities Conducting campus culture is an essential extra-curricular activity for college students. College students will be influenced and affected by campus culture, so teachers must pay attention to development of campus cultural activities in the process of teaching, taking campus as a good promotional platform for guidance and publicity of Chinese core values to enhance students' sense of identity for Chinese culture and values. For example, teachers can organize students to engage in cultural festivals, film festivals and other activities, and guide students to establish the correct values through different activities, and to face with various social phenomena with a positive and healthy attitude. During foreign language teaching, teachers should take extracurricular activities as an important teaching method to enhance the students' communication skills through extracurricular activities. For example, teachers can organize Chinese students and western students to conduct drama performances to enhance students' communication skills, and strengthen students' understanding of western culture core concepts in the course of performing, and then they can select positive values to be used. English teachers in colleges and universities should have a certain sense of responsibility and professionalism, in the face of deepening western culture in the society, adhere to Chinese core values, and cultivate diversified sprite, to enhance students' ability of international communication.

\section{Conclusions}

In summary, during international communication, difference of Chinese and western values would lead to contradictions and conflicts. College English teachers should pay attention to the important role of values in international communication. In the diversified society, teachers should encourage students to understand western culture and values, and cultivate students to establish core values consistent with the social development in China, fundamentally lifting students' international communication skills.

\section{Acknowledgments}

This paper is part research result of 2015 Hebei Social Science Development Research. Project Number: 2015020503.

\section{References}

[1] Li Siqing. On Autonomous Ability of College English Teachers. Shanghai International Studies University, 2013.

[2] Lu Xu. Construct Core Values to Enhance Cultural Soft Power -Reflections on Cultural Teaching in College Foreign Language Education. Journal of Harbin Institute of Technology, 2011 (04).

[3] Li Zhouhong. College Foreign Language Teaching and Cultivation of Chinese Culture Core Values. Journal of Shijiazhuang Railway University (Social Science Edition), 2011 (02). 
[4] Tong Xiafang. Chinese Traditional Culture Heritage and Criticism in Cultivation of Socialist Core Values Cultural. Journal of Zhejiang University of Technology (Social Science Edition), 2015 (02). 